\title{
The Effects of Antibacterial and Flame Resistance Finishing to the Comfortable Properties of Cotton/Bamboo Pulp Interwoven Fabric
}

\author{
$\operatorname{JinYu~XU}{ }^{1, a}$ \\ ${ }^{1}$ College of Textile and Dyeing Engineering, Jiangsu College of Engineering and Technology, \\ Nantong; Jiangsu;226007, China \\ axjyxp@qq.com
}

Keywords: interwoven fabric, antibacterial finishing, flame resistance finishing, bamboo pulp fiber, air permeability, water vapor permeability

\begin{abstract}
In order to better study the effects of antibacterial and flame resistance finishing to the properties of cotton/bamboo pulp interwoven fabric, a kind of cotton/bamboo pulp interwoven fabric was designed and woven. Fabric properties before and after antibacterial and flame resistance finishing like air permeability, water vapor permeability, water absorption, dimensional stability to washing, etc. were tested. The results show that air permeability, water vapor permeability, water absorption after antibacterial and flame resistance finishing are worse than those of before finishing. Dimensional stability to washing after antibacterial and flame resistance finishing was better than those of before finishing.
\end{abstract}

\section{Introduction}

Functional textiles are extending continuously in actual life with the development of economy and living standard [1,2]. Antibacterial fabric, flame resistance fabric, anion fabric, heat accumulation and warmth retention fabric, far-infrared fabric and other functional fabrics are favored by consumers $[3,4,5]$. Study the properties before and after antibacterial and flame resistance finishing of cotton/bamboo pulp interwoven fabric has important economic and practical value [6]. A kind of cotton/bamboo pulp interwoven fabric was designed and woven. Fabric properties before and after antibacterial and flame resistance finishing like air permeability, water vapor permeability, dimensional stability to washing, etc. were tested and analyzed. 


\section{Fabric structure and specification parameters}

The fabric was used 14.5tex cotton warp yarns and 14.5tex bamboo pulp weft yarns woven on JAT710 air jet looms, density of warp yarn was 433 roots $/ 10 \mathrm{~cm}$, density of weft yarn was 315 roots $/ 10 \mathrm{~cm}$, width was $146.5 \mathrm{~cm}$. In order to accurately measure the properties before and after antibacterial and flame resistance finishing like air permeability, water vapor permeability, water absorption, dimensional stability to washing etc, and avoid error introduced by the size and impurities, the fabric was desized using amylase and then rinsed with cold water 2-3 times, dry in the air, placed in standard atmospheric conditions over $48 \mathrm{~h}$, made the fabric got equilibrium under absorption state[7].

\section{Antibacterial and Flame Resistance Finishing}

Using ATB9800 antibacterial/odor-resistant finishing agent and FPK8002 flame retardant [8]. ATB9800 antibacterial/odor-resistant finishing agent was a non-dissolution-type durable antibacterial finishing agent. ATB9800 had good security, it could effectively remove the bacterial, fungi and mildew of fabric, keep the fabric clean, and prevent the regeneration and reproduction of bacterial. ATB9800 antibacterial/odor-resistant finishing agent was fixed to the fibers because active groups of ATB9800 could form covalent bonds with Hydroxyl group or amine group of fibers, it had a reliable washable broad-spectrum antibacterial effect. The antibacterial principle was that it destroyed the cell wall of bacteria, the intracellular osmotic pressure was higher than extracellular osmotic pressure, so the cell membrane ruptured, cytoplasm disclosed. This would terminate the metabolic processes of microorganism, so that micro-organisms could not grow and reproduce. FPK8002 flame retardant could be applied to the padding process.

Antibacterial finishing: fabric $\rightarrow$ padding antibacterial solution (padding temperature $30^{\circ} \mathrm{C}$, ATB9800 40g/L; pick up ratio $60 \sim 90 \%$, the working fluid volume is small $) \rightarrow$ drying $\left(110^{\circ} \mathrm{C}\right) \rightarrow$ tentering $\left(140^{\circ} \mathrm{C} \times 30 \mathrm{~s}\right) \rightarrow$ remove fabric

Flame resistance finishing: fabric $\rightarrow$ padding (FPK8002 350g/L; two dip two rolling, pick up ratio $60 \sim 80 \%) \rightarrow$ drying $\left(90{ }^{\circ} \mathrm{C}\right) \rightarrow$ baking $\left(120^{\circ} \mathrm{C} \times 4 \mathrm{~min}\right) \rightarrow$ remove fabric.

\section{Test equipment, test parameters and Executive standards}

The Test equipment, test parameters and executive standards were shown in Table 1 . The test data such as air permeability, water vapor permeability, water absorption, dimensional stability to washing were shown in Table 2. 
Table 1 Test equipment, test parameters and implementation of standards

\begin{tabular}{|c|c|c|c|}
\hline Test items & Test equipment & Executive standards & Test parameters \\
\hline Air permeability & $\begin{array}{l}\text { YG461D digital fabric } \\
\text { permeability meter }\end{array}$ & $\begin{array}{l}\text { GB/T } 5453-1997 \\
\text { Textiles--Determination of the } \\
\text { permeability of fabrics to air }\end{array}$ & $\begin{array}{l}\text { Area: } 20 \mathrm{~cm}^{2} ; \\
\text { Pressure drop: } 100 \mathrm{~Pa}\end{array}$ \\
\hline Water vapor permeability & $\begin{array}{l}\text { YG601 moisture } \\
\text { permeability box }\end{array}$ & $\begin{array}{l}\text { GB/T 12704.1-2009 Textiles--Test } \\
\text { method for water-vapour transmission } \\
\text { of fabrics--Part 1:Desiccant method }\end{array}$ & Diameter: $70 \mathrm{~mm}$ \\
\hline Water absorption & $\begin{array}{l}\text { YG871L capillary effect } \\
\text { testing instrument }\end{array}$ & $\begin{array}{c}\text { GB/T21655.1-2008 } \\
\text { Textiles_-Evaluation of absorption and } \\
\text { quick-drying — Part 1:Method for } \\
\text { combination tests }\end{array}$ & Size: $10 \mathrm{~cm} \diamond 10 \mathrm{~cm}$ \\
\hline Washing resistance & $\begin{array}{l}\text { YG701 automatic testing } \\
\text { machine of shrinkage rate }\end{array}$ & $\begin{array}{l}\text { GB/T8629-2001 Textiles-Domestic } \\
\text { washing and drying procedures for } \\
\text { textile testing; } \\
\text { GB/T 8630-2013 Determination of } \\
\text { textile dimensional change in washing } \\
\text { and drying }\end{array}$ & $\begin{array}{l}\text { Size: } \\
500 \mathrm{~mm} \diamond 500 \mathrm{~mm} \text {, } \\
\text { washing time }: 15 \mathrm{~min}\end{array}$ \\
\hline
\end{tabular}

Table 2 Fabric properties before and after antibacterial and flame resistance finishing

\begin{tabular}{|c|c|c|c|c|}
\hline \multirow{2}{*}{ Indexes } & \multicolumn{2}{|c|}{ Before finishing } & \multicolumn{2}{c|}{ After finishing } \\
\cline { 2 - 5 } & Warp & Weft & Warp & Weft \\
\hline dimensional stability to washing $/ \%$ & -4.1 & -2.1 & -3.1 & -1.6 \\
\hline air permeability $/ \mathrm{mm} . \mathrm{s}^{-1}$ & \multicolumn{2}{|c|}{328} & \multicolumn{2}{|c|}{161} \\
\hline water vapor permeability $/ \mathrm{g} .\left(\mathrm{m}^{2} * 24 \mathrm{~h}\right)$ & \multicolumn{2}{|c|}{9660} & \multicolumn{2}{|c|}{103} \\
\hline water absorption $/ \%$ & \multicolumn{2}{|c|}{127} & \multicolumn{2}{|c|}{} \\
\hline
\end{tabular}

Air permeability, water vapor permeability, water absorption, dimensional stability to washing were tested by Nantong Textile Quality Testing Institution Co., Ltd, Report NO: 16157431.

\section{Analysis of test results}

\subsection{Analysis of air permeability}

The air permeability of fabrics depended on the number and size of warp and weft yarns in the fabric, such as the warp and weft density, the warp and weft count, fiber properties, yarn structure, thickness of fabric and weight per unit area and so on. the air permeability was greater; the air permeability of the fabric was better [9]. According to Table 2, after finishing, the air permeability of fabric decreased a lot, up to $50.9 \%$. The antibacterial agents and flame retardants adhered to the fabric, the gap of the fabric decreased, this caused the air permeability of fabric decreased. 


\subsection{Analysis of water vapor permeability}

Water vapor permeability of fabric was an important comfort, health performance, it was directly related to the ability to discharge sweat steam [10]. No matter what the season, the body would continue to distribute sweat steam, if the sweat steam quickly distributed out through the fabric, the body would feel comfortable. Water vapor permeability was a measure of moisture permeability of the fabric index, the amount of moisture was larger, sweat steam emitted faster [11]. According to Table 2, water vapor permeability decreased $2.9 \%$ after finishing. The antibacterial agents and flame retardants adhered to the fabric, the gap of the fabric decreased, this caused the water vapor permeability of fabric decreased.

\subsection{Analysis of dimensional stability to washing}

Dimensional stability to washing of fabrics or other textile products had a great impact on the specifications. According to Table 2, before finishing, warp dimensional stability to washing was $-4.1 \%$, weft dimensional stability to washing was $-2.1 \%$; after finishing, warp dimensional stability to washing was $-3.1 \%$, weft dimensional stability to washing was $-1.6 \%$.

\subsection{Analysis of water absorption}

Water absorption refered to the percentage of the moisture absorbed by the fabric to the original quality of the fabric when the fabric was completely wetted out of the water and no water was dripped. According to Table 2, water absorption before finishing was $127 \%$, water absorption after finishing was $103 \%$. After finishing, a small number of hydrophilic groups of cotton and bamboo pulp fiber were closed, moisture regain decreased, thus the water absorption of fabric was affected.

\section{Conclusions}

(1) After finishing, the air permeability and water vapor permeability of fabric decreased.

(2) After finishing, dimensional stability to washing increased.

(3) After finishing, water absorption of fabric decreased.

\section{References}

[1]WANG Wen-zhong, ZHAO Lei, CHEN Chun-xia, etc. The production practice of antimicrobial, warm composite fabric containing silver and carbon[J]. shanghai textile science \& technology, 2015, 43 (7) : 42-44 [2]MA Shun-bin, CAI Yong-dong. Flame Resistance Property Study of Polyester Cotton Blended Intertexture[J].Cotton Textile Technology, 2015, 43 (1) : 29-31, 60

[3]WENG Liang, WU Zan-min. Finishing of Fabric for Heat Accumulation and Warmth Retention[J].Textile Dyeing and Finishing Journal,2005,27 (8) : 6-9

[4]YANG Wei-jun, GE Ming-qiao, LI Yong-gui,etc. Factors affecting anion-generating capacity of anion fabric[J]. Journal of Textile Research,2006,27 (12) : 88-91

[5]HANG Ping, ZHANG Wei-hua. Testing and evaluating of far-infrared fabric's warmth retention property[J]. Journal of Xi' an Polytechnic University,2010,24 (1) : 11-16 
[6]WANG Qi. Study on Properties of Soybean Fiber and Knitted Fabrics with Quick Wet Permeability and Drying Functions[D], Shanghai: DONG HUA UNIVERSITY,2002

[7]QIAN Shi-ru. Research on enzymatic desizing and its mechanism of cotton yarn dyed fabric[D].WU XI:JIANGNAN UNIVERSITY,2014

[8]LI Ya-hui. Practice of Anti-bacterial and Odor-Resistant finishing of Fabrics[J]. Textile Dyeing and Finishing Journal,2008,28(3):31-34,47

[9]CHEN Zhi-hua, MA Shun-bin. Influence of bamboo pulp fiber content and weft density on its transparent of bamboo/cotton fabric[J]. Shanghai Textile Science \& Technology,2009,37(12):13-15

[10]TANG Jian-dong,WANG Ping,LI Li-cheng . Wearability Research of Cotton Bamboo Hemp Blended Fabric[J]. Cotton Textile Technology, 2012, 40 (2) : 8-10

[11]ZHU Wei-wei.The Research of Microclimate State Under Clothing and The Measurement of Moisture Resistance for Fabric[D]. Shanghai: DONG HUA UNIVERSITY,2014 